REVISIÓN
Rev Colombiana Cienc Anim 2018; 10(1):86-97.

\title{
Características agronómicas y calidad nutricional de los frutos y semillas de zapallo Cucurbita sp.
}

\author{
Agronomics characteristics and nutritional quality of fruits and seeds of \\ pumpkin Cucurbita sp.
}

\author{
Rodríguez R, Robert M.Sc; Valdés R, Magda² Ph.D; Ortiz G, Sanin ${ }^{1 *}$ Ph.D. \\ ${ }^{1}$ Universidad Nacional de Colombia, Facultad de Ciencias Agropecuarias, Palmira, Valle del Cauca, Colombia. \\ ¿Universidad de San Buenaventura, Facultad de Ingeniería, Grupo de investigación Biotecnología, Cali, Colombia.
}

\section{KEYWORDS:}

Agribusiness; butternut squash;

Cucurbita;

Carotenoids;

lutein;

starchs.

\section{ABSTRACT}

The Butternut Squash is food security in ancient pre-Columbian America for its agronomic plasticity and culinary versatility. Today its value in use is evident in both its diversity within the genus Cucurbita and 20-27 species, where the most used are: Cucurbita maxima, C. moschata, C. pepo, C. argyrosperma; C. ficifolia. The high biological value in the pulp ( $80 \%$ in vitro digestibility) and oil in the seeds (45\%), where $55 \%$ are unsaturated (56\% linoleic acid) fatty. The processed pumpkin is a competitive and sustainable raw material for agro food industry, and is a source of carotenoids, lutein, Vitamima A, Vitamin C, starch, long chain polyunsaturated oils, and this entire means an increase in research in squash due to its comprehensive utility in the pulp and seed.

\section{PALABRAS CLAVE:}

\section{Ahuyama;}

agroindustria;

Cucurbita;

carotenoides;

luteína;

almidones.

\section{RESUMEN}

El zapallo es seguridad alimentaria en América ancestral precolombina por su plasticidad agronómica y versatilidad culinaria. En la actualidad su valor de uso es evidente, tanto en su diversidad dentro del género Cucurbita y sus 20 a 27 especies, donde las más utilizadas son: Cucurbita maxima, C. moschata, $C$. Pepo, C. argyrosperma; C. ficifolia. El alto valor biológico en la pulpa $(80 \%$ de digestibilidad in vitro) y aceite en las semillas (45\%), donde el $55 \%$ son ácidos grasos insaturados (56\% de ácido linoleíco). El zapallo procesado es una materia prima competitiva y sostenible para la industria agroalimentaria, y es fuente de carotenoides, luteina, Vitamima A, Vitamina C, almidones, aceites polinsaturados de cadena larga, y todo ello supone un aumento en la investigación en zapallo debido a su utilidad integral, tanto en la pulpa como en la semilla. 


\section{INTRODUCCIÓN}

Las especies domesticadas del género Cucurbita probablemente sean las plantas útiles más antiguas de América, a juzgar por los hallazgos arqueológicos efectuados en Mesoamérica (Tehuacán, México) y en los Andes Centrales (Huaca Prieta, Perú) (CARTAY, 1991). En el Valle de Oaxaca, exactamente en la gruta de Guilá Naquitz, se encontró el más antiguo testimonio fiable de actividad agrícola, correspondiente a un fragmento de una calabaza comestible Cucurbita pepo, de hace 8000 años (SMITH, 1997). Por miles de años las especies del genero Cucurbita, el maíz Zea mays, el frijol Phaseolus y los chiles Capsicum constituyeron componentes importantes de la dieta de las sociedades precolombinas (CARTAY, 1991).

Parece ser que las Cucúrbitas se utilizaron mucho antes que la cerámica en la elaboración de recipientes para transportar agua, chicha, miel etc. Se tiene evidencias en la cultura Quimbaya (Colombia) sobre vasijas en cerámica con forma de calabazas utilizadas en sus actividades caseras (PÉREZ, 1978). Los registros arqueológicos indican que las especies del género Cucurbita encontradas se han obtenido en zonas muy áridas $\mathrm{y}$, ello supone fragmentos de corteza, semillas y pedúnculos de los frutos como la mejor herramienta de diagnóstico, aunque es raro encontrarlos intactos, pero ocasionalmente se ha logrado (WHITAKER y CUTLER, 1971).

Desde el punto de vista socio económico, el género Cucurbita es importante por formar parte de la alimentación básica en diversas regiones de América, Asia y Europa (VALLEJO y ESTRADA, 2004). Esta importancia se refleja en el aumento del área sembrada. En el año 2011, en el mundo se sembraron 1.774.000 millones de hectáreas, destacándose la India con 502 mil has, China con 377 mil y Camerún con 119 mil (FAOSTAT, 2013). En Colombia, en 2010, se sembraron 3800 has, con un rendimiento promedio de 17 t/ha. En 2011 se sembraron 3411 has, con un rendimiento promedio de 19.8 t/ha (FAOSTAT, 2013). Esto es explicable, si se tiene en cuenta que la mayoría de las variedades de zapallo sembradas en Colombia corresponden a la especie Cucurbita moschata, la cual es mejorada genéticamente para calidad en la pulpa y rendimiento por hectárea (VALDÉS et al., 2014).

Sus frutos, con un alto contenido de carbohidratos, vitaminas, fósforo y fibra, y sus semillas, ricas en aceites y proteínas, como también las flores y puntas de los tallos, jugaron un papel importante en el surgimiento de la agricultura y en la manutención del hombre prehispánico, pues suministraba un alimento abundante y de fácil propagación (CARTAY, 1991), además, el hombre domesticó las Cucúrbitas no por la pulpa sino por las semillas (ESTRELLA, 1990), se podían encontrar Cucúrbitas con una amplia cavidad placentaria repleta de semillas, con escasa pulpa de sabor amargo. Con el pasar del tiempo, el hombre realizó una evolución dirigida hacia la pulpa, aumentando el espesor de pared, color, sabor y más recientemente, con métodos de mejoramiento genético convencional, incrementó el contenido macromolecular (almidón, carotenos, proteína) en la pulpa de zapallo (VALDÉS et al., 2010).

En Cucúrbitas se presenta variantes para el color de la semilla: desde blanco al café, que pueden tener significado evolutivo y de distribución geográfica (VALDÉS et al., 2014). La mayor parte de las variedades crecieron durante el periodo precolombino a altitudes muy elevadas en los Andes y sus frutos presentaban semillas de color café y las cultivadas a bajas altitudes presentaban semillas de color blanco (SINGH, 1990). La identificación de las formas ancestrales y el lugar de origen han sido el mayor tópico de investigación en este género; sin embargo, poco se conoce sobre la semilla como fuente de energía por su alto contenido de extracto etéreo (ORTIZ et al., 2013).

La importancia del zapallo en la seguridad alimentaria a nivel nacional y la creciente demanda de nuevas materias primas para la agroindustria, viene fomentando de manera progresiva la investigación sobre esta hortaliza (VALDÉS, 2010). Lo que convierte al zapallo o ahuyama, como una alternativa no convencional, competitiva y sostenible, ya que al aumentar la materia seca en el fruto, se tienen procesos más eficientes y productivos en la agroindustria de alimentos balanceados para animales, en especial en la operación unitaria más costosa en la agroindustria de frutos suculentos: el deshidratado (VALDÉS et al., 2010).

\section{GENERALIDADES DE LAS CUCÚRBITAS}

La familia Cucurbitaceae, de acuerdo con la clasificación más reciente, contiene 118 géneros y alrededor de 825 especies, uno de los géneros más importantes es Cucurbita, en el cual se consideran de 20 a 27 especies (JEFFREY, 1990). Sin embargo, la clasificación propuesta por LIRA (1995) reconoce dentro de éste género sólo 15 especies. Según NEE (1990), el género se puede reducir a 12 o 13 especies, once de las especies silvestres se encuentran en México y dos en América del Sur. Dentro del género Cucurbita se destacan cinco especies domesticadas: Cucurbita argyrosperma Huber, C. ficifolia Bouché, C. maxima Duchesne, C. pepo L. y C. moschata (Duchesne ex lam) Duchesne ex Poir, las cuales fueron domesticadas en el Nuevo Mundo y durante milenios han sido cultivadas. C. moschata es la más extendida en América tropical, desde México hasta el Perú (WHITAKER, 1981). La mayor parte de las especies silvestres del genero 
Cucurbita se distribuyen en regiones relativamente pequeñas del continente Americano y solo algunas como Cucurbita foetidissima (Estados Unidos al centro de México) y Cucurbita argyrosperma ssp. sororia (México a Centroamérica) se hallan ampliamente distribuidas (SANJUR et al., 2002).

Estudios de LIRA (1995), señalaron que la variabilidad en el género Cucurbita se encuentra en la morfología, tamaño de frutos y semillas, coloración, tipo y sabor de mesocarpio. El número de cromosomas de todas las especies de Cucurbita es $2 n=2 x=40$, los cariotipos sugieren que estas especies son de origen alopoliploide (LEBEDA et al., 2007). Sin embargo, a pesar de su alto grado de diferenciación, ninguna de las especies del género Cucurbita está completamente aislada en términos reproductivos (CERÓN et al., 2010).

Las Cucúrbitas se caracterizan por su hábito trepador o rastrero, presencia de zarcillos, flores unisexuales y vistosas, polinización entomófila, ciclo vegetativo anual o perennes, plantas herbáceas y usualmente monoicas, pero hay andromonoícas y dioicas (NEE, 1990; LIRA, 1995). Por su hábitat y ciclo de vida se han dividido en dos grandes grupos: mesofiticas (anuales o perennes de vida corta, raíz fibrosa, no tuberosa, habitan en climas de gran aridez) y xerofítica (perennes, raíz engrosada y tuberiforme, que prosperan en zonas de aridez alta o muy extrema) (SMARTT y SIMMONDS, 1995).

El género Cucurbita según HIDALGO y VALLEJO, (2014), ha jugado un papel importante en lo que tiene que ver con la alimentación, medicina, artesanías, ornamentación, agroindustria, utensilios para el hogar, actividades folclóricas y cultos religiosos, entre otras. Desde el punto de vista etno-botánico, las especies domesticadas del género Cucurbita tienen valor debido a: Versatilidad tanto en consumo directo (sopas, cremas, dulces, purés, jugos, pastelería y compotas) y como materia prima para la agroindustria (harinas, aceites, deshidratados); altas calidades alimenticias relacionadas con el contenido de carotenos (provitamina $\mathrm{A}$ ), ácido ascórbico (vitamina $\mathrm{C}$ ), minerales (calcio, hierro, fosforo) y aminoácidos (niacina y tiamina); Alto volumen de producción (20-30 Kg/planta); alimento saludable; Mercado con gran potencial de exportación, especialmente a los países europeos; Cultivos ligados a los pequeños agricultores de muchas áreas cálidas y templadas (0 o 2000 m.s.n.m.); Cultivos con gran potencial para la producción de aceites y biodiesel a partir de la semilla; materia prima para la elaboración de artesanías.

\section{Identificación de las especies cultivadas de las Cucúrbitas}

Según VALLEJO y ESTRADA (2004), la forma de los pedúnculos se ha usado como característica para diferenciar las especies de Cucurbita. WHITAKER y DAVIS (1961), presentaron algunas claves para diferenciar las especies cultivadas de Cucurbita:

C. argyrosperma: pedúnculo duro, diámetro muy ensanchado de corcho duro; no ensanchado al unirse al fruto, hojas sin espinas. C. ficifolia: planta perenne con semillas negras o morenas. C. máxima: tallos suaves y redondos; pedúnculo redondo agrandado por tejido corchoso. Hojas redondas sin manchas blancas, semilla blanca. C. moschata: tallos duros y angulares; pedúnculo suavemente acanalado (pentaquínado) ensanchado en el punto de unión con el fruto. Hojas sin espinas pero con vello suave y con manchas blancas en la intersección de las nervaduras. C. pepo: tallos duros y angulares; pedúnculo angular y acanalado (pentaquinado) y hojas con espinas finas.

Especies domesticadas del género Cucurbita

C. argyrosperma: Las subespecies argyrosperma y sororia se cultivan desde el nivel del mar hasta los 1900 msnm, en zonas cálidas y secas, no toleran temperaturas bajas. La diversidad, comparada con las otras especies domesticadas, es menor, presenta razas o variedades locales y algunos cultivares, producidos en los Estados Unidos (VALLEJO y ESTRADA, 2004).

Está especie constituida por dos subespecies: argyrosperma y sororia. La subespecie argyrosperma, está formada por cuatro variedades: argyrosperma, callicarpa, stenosperma y palmieri. Las tres primeras variedades incluyen a todos los tipos cultivados, mientras que la cuarta corresponde a poblaciones silvestres relacionadas (MERRICK, 1990).

La subespecie sororia comprende poblaciones silvestres de amplia distribución desde México hasta Nicaragua, siendo ésta el ancestro silvestre de la especie domesticada (WHITAKER, 1981). Restos arqueológicos se han encontrado desde el sudeste de los Estados Unidos hasta el centro - sur de México y sugieren que la domesticación de ésta especie debió llevarse a cabo en ésta región hace más de 7.000 años (HERNÁNDEZ y LEÓN, 1994). La razón de su escasa difusión a nivel mundial es probablemente la baja calidad de la pulpa, comparada con la de C. moschata o C. pepo (VALDÉS, 2014).

Se han propuesto dos hipótesis para explicar el origen y evolución de las formas cultivadas de C. argyrosperma. La primera sugiere que cada una de las variedades cultivadas fue domesticada de manera independiente a 
partir de poblaciones de la subespecie sororia, mientras que la otra propone a la variedad argyrosperma como la primera en haberse seleccionado y que a partir de esta se derivaron las dos restantes variedades cultivadas (VALLEJO y ESTRADA, 2004).

C. ficifolia: El origen de ésta especie aún no está definido. Algunos investigadores han propuesto que su origen es centroamericano o mexicano, mientras que otros sugieren a los Andes. Sin embargo las evidencias arqueológicas inclinan la balanza hacia un origen suramericano (WHITAKER y BEMIS, 1975). Se encuentra distribuida en las cordilleras de Suramérica, entre $1000-3000$ msnm (HERNÁNDEZ y LEÓN, 1994). Es la especie menos diversa del género en comparación con las otras cuatro especies cultivadas y no se conocen todavía cultivares comerciales. Las variaciones más importantes se presentan en la coloración y dimensiones de sus frutos y semillas (frutos blancos a verdes con diferentes patrones de manchas o franjas blancas y semillas pardo claras a pardo oscuras o negras) (LIRA, 1995).

C. maxima: Fue domesticada en América del Sur (WHITAKER, 1962). Restos arqueológicos se han encontrado desde Perú hasta el Norte de Argentina. $C$. andreana y $C$. ecuadorensis son las especies silvestres más relacionadas, siendo la primera el ancestro silvestre más probable (CUTLER y WHITAKER, 1969). Es una de las especies más diversas del género, incluye razas o variedades locales y abundantes cultivares con hábitos rastreros y arbustivos, con frutos y semillas muy variables en su forma, tamaño y coloración y diferentes niveles de resistencia a enfermedades. Se cultiva ampliamente en Suramérica y en Estados Unidos, desde los $100 \mathrm{~m}$ hasta los $3000 \mathrm{msnm}$ (LIRA, 1995).

C. moschata: Especie domesticada en Suramérica, aunque no existe acuerdo sobre el área precisa de su domesticación (WHITAKER, 1947). Se ha mencionado que el norte de Colombia es posiblemente el centro de origen (SANJUR et al., 2002). Restos arqueológicos de 4.900 - 3.500 a.C se han encontrado en Centroamérica, Suramérica y Noreste de México (LIRA, 1995).

Sobre el origen de C. moschata se han propuesto dos hipótesis, la primera sugiere que ésta especie se originó a partir de poblaciones de $C$. Iundeliana por aislamiento y procesos de selección humana (WHITAKER, 1981), mientras que la segunda propone que ambas especies proceden de un ancestro común y que debido a las fuertes presiones humanas, C. moschata se separó rápidamente del ancestro común, como de $C$. lundeliana, pero uno de los principales argumentos en contra de esta hipótesis es la capacidad de C. moschata para producir híbridos fértiles con las taxas silvestres del grupo C. argyrosperma (MERRICK, 1990), además, algunas diferencias morfológicas entre $C$. lundelliana y
C. moschata (color de semilla azul-grisáceo verdoso de $C$. lundelliana que no se ha encontrado en C. moschata) y las evidencias derivadas del estudio de biología molecular, indican que hasta ahora no se ha identificado el ancestro silvestre (PUCHALSKI y ROBINSON, 1990).

Es una especie muy variable, ampliamente distribuida y la mejor representada en los bancos de germoplasma de América. Se presentan muchas introducciones locales en el norte de Colombia y últimamente se han reportado poblaciones silvestres en Colombia y Bolivia que pudieran estar relacionadas con C. moschata. Es un cultivo que prospera bien en zonas de baja altitud (prosperando hasta los $2.300 \mathrm{msnm}$.) y clima cálido y con alta humedad (VALLEJO y ESTRADA, 2004). Existen dos variantes de color de semilla (blanco y café) lo que puede ser indicativo de su linaje evolutivo y su patrón de distribución (VALDÉS, 2014).

C. pepo: C. pepo fue una de las primeras especies del género Cucurbita en haber sido domesticada, sus restos más antiguos se han encontrado en México (Valle de Oaxaca, 8750 a.C - 700 d.C) (LIRA, 1995). Las especies silvestres más relacionadas a $C$. pepo son: C. fraterna y C. texana (ANDRÉS, 1987).

C. pepo está constituida por solo tres subespecies: la subespecie pepo que incluye a todos los cultivares comestibles y ornamentales y las subespecies texana y fraterna, correspondientes a los ancestros silvestres del grupo (DECKER-WALTERS et al., 2002). Es la segunda especie mejor representada en los bancos de germoplasma de Cucurbita en cuanto a especies cultivadas, pero sus dos parientes más cercanos ( $C$. fraterna y C. texana) son muy escasos (NEE, 1990).

Es una especie que crece en condiciones ecológicas bastante amplias, desde el nivel del mar hasta los 2000 msnm, es probablemente la especie que presenta mayor susceptibilidad a las enfermedades virales que atacan a las especies cultivadas de Cucúrbitas. La diversidad de C. pepo es comparable o muy probablemente superior a la de C. máxima, (LIRA, 1995).

\section{Especies silvestres del género Cucurbita}

Cucurbita ecuadorensis: se encuentra en las zonas secas y bajas de la costa del Ecuador (VALEGA et al., 2004). Existe un registro arqueológico de la costa Peruana, que data de hace 10.000 años, pero no se conocen otras evidencias que confirmen su presencia en la zona (PIPERNO y STOTHERT, 2003). Se híbrida fácilmente con C. maxima ssp. maxima y con su ancestro silvestre C. maxima ssp. andreana y en menor grado con otras especies cultivadas y silvestres. Es una fuente importante de resistencia a enfermedades vírales (PROVVIDENTI, 1990). 
Cucurbita lundelliana: se encuentra distribuida desde el sur de México hasta Centro América. Prospera a bajas altitudes (WHITAKER, 1981). Contiene frutos amarillos o naranjas, semilla de color azul o gris verdoso. Se relaciona con C. okeechobeensis ssp. okeechobeensis y martinezii pero difiere de estas por las márgenes de las semillas más engrosados. Posee hojas similares a $C$. ficifolia. Es una especie resistente al moho polvoriento (LIRA, 1995). Whitaker citado por ROBINSON et al., (1976), verificó que C. lundelliana es resistente a oidio y es heredada en forma simple y dominante (Pm: Resistencia al mildeo polvoso) en cruzamientos con C. moschata.

Cucurbita okeechobeensis ssp. okeechobeensis: especie endémica de los pantanos del suroeste de la Florida, Estados Unidos. Es una especie en peligro de extinción (LIRA, 2001).

Cucurbita okeechobeensis ssp. martinezii: sólo ha sido colectada en la vertiente del Golfo de México, desde el sur de Tamaulipas hasta el norte de Oaxaca y Chiapas. Se encuentran en ríos y bosques caducifolios, y en selvas bajas y medianas desde el nivel del mar hasta los $1500 \mathrm{~m}$. (LIRA, 2001).

Cucurbita digitata: las plantas son esencialmente rastreras y perennes. Se distribuye desde el sureste de los Estados Unidos al noreste de México. Al igual que $C$. cordata y $C$. palmata prospera en condiciones cálidas y áridas con poca lluvia, con las cuales hibrida con facilidad (BEMIS y WHITAKER, 1969). Puede soportar sequías hasta de 20 meses. Son conocidas comúnmente como adavi, adwi, pima, papago, arizona, melón coyote, calabacilla. En su área de distribución coexiste con algunas poblaciones de C. palmata, presentándose algunos híbridos naturales entre las dos especies (LIRA, 1995).

Cucurbita cordata: Posee plantas rastreras, perennes, endémica de México (NEE, 1990). Comúnmente se conoce como calabacita amarga o melón cimarrón (WATSON, 1879).

Cucurbita palmata: Las plantas son rastreras, raramente trepadoras, prospera en zonas áridas y semiáridas y se distribuye desde Estados Unidos hasta México (BEMIS y WHITAKER, 1969).

Cucurbita foetidissima: Las plantas son esencialmente rastreras, con raíces tuberosas y xerófilas que generalmente expiden un olor fuerte. Se distribuye ampliamente desde los Estados Unidos hasta el centro de México. Ha sido muy estudiada debido a los altos contenidos de aceite y proteína de sus semillas y por los almidones de sus raíces. Es resistente a algunas enfermedades vírales, sin embargo, presenta dificultad para hibridar con otras especies del género, que no ha permitido su uso inmediato en programas de mejoramiento (BEMIS et al., 1978).

Cucurbita pedatifolia: La planta es herbácea rastrera a trepadora, perennes, frutos ovalados, pulpa de color blanquecino verdoso, raramente anaranjado pálido, muy fibrosa y de sabor amargo (BAILEY, 1943). Es endémica de México y prospera en zonas secas y frías que superan los 1350 m.s.n.m. (NEE, 1990). Se conoce comúnmente como calabacilla, calabacilla cimarrona, torito. Es una de las pocas especies del género que híbrida con $C$. ficifolia; sin embargo, la progenie no alcanza la segunda generación; esta especie, es resistente a varias enfermedades vírales pero su escasa compatibilidad impide su aprovechamiento (LIRA, 1995).

Cucurbita radicans: La planta es herbácea, rastrera y perenne. Fruto muy similar a C. pedatifolia. Es una especie endémica de México y prospera en alturas (LIRA, 2001).

\section{Importancia económica del zapallo}

A nivel mundial el cultivo de zapallo es importante, pues de 1994 al 2001 el área sembrada se ha incrementado en un $34 \%$, al pasar de 564 a 1297 millones de hectáreas y del 2002 al 2007 entre 1432 a 1546 millones de hectáreas sembradas, en donde se destacan los Estados Unidos, México, India, china, la isla de Malta, Australia y Nueva Zelanda como los productores más grandes de zapallo (WHF, 2008). La productividad por hectárea en la Isla de Malta, Austria, Holanda, Israel y España que en el 2001 osciló entre 35 y 50 t/ha, ha crecido a ritmo constante en los últimos 5 años, hasta alcanzar rendimientos de 42, 72 y 92 t/ha para Austria, Holanda y la Isla de Malta respectivamente (www. faostad.org). Es Italia el segundo productor de zapallo Cucurbita moschata Duch., en Europa, después de Ukrania, en especial porque el consumo incrementó en $10 \%$ por año en la última década (LACUZZO y DALLA COSTA, 2009). Según KRAUTGARTNER (2006), Austria es el país europeo que le ha dado marcha hacia adelante a la producción de reemplazo de combustibles fósiles por aceites de semillas de oleaginosas y, en ese sentido, ya presenta en sus estadísticas al aceite de semilla de zapallo como una parte de la oferta, con un $3 \%$ de la producción nacional. Lo anterior demuestra que el zapallo es una fuente importante de biocombustible proveniente de las semillas y de nutrientes en la pulpa del fruto para los alimentos balanceados para animales (ORTIZ et al., 2013).

Si bien en Colombia para el periodo comprendido entre el 2005 y 2010 el área sembrada de zapallo fluctuó entre 3510 y 3800 hectáreas, su productividad mejoró 
moderadamente, pues para esos mismos años pasó de 16.6 a $17.1 \mathrm{t} / \mathrm{ha}$, sin embargo, los reportes más actuales indican que el área sembrada de Cucúrbitas en el 2011 fue de 3411 hectareas las cuales produjeron 19.8 t/ha (FAOSTAT, 2013). Esto es explicable, si se tiene en cuenta, que la mayoría del zapallo sembrado en Colombia es de la especie Cucurbita moschata, especie mejorada genéticamente por calidad en la pulpa y rendimiento por hectárea. Sobre la especie Cucurbita argyrosperma subsp. sororia, no se tienen reportes en Colombia de su uso a nivel comercial o local (VALDÉS, 2014).

En Colombia se ha incrementado la producción de zapallo debido a la versatilidad tanto en consumo directo (sopas, cremas, dulces, purés, jugos, pastelería y compotas), como en el uso de materia prima para la agroindustria (harinas y deshidratados) y las altas calidades alimenticias relacionadas con el contenido de carotenos (provitamina A), ácido ascórbico (vitamina $\mathrm{C}$ ), minerales (calcio, hierro, fósforo) y aminoácidos como tiamina y niacina (VALLEJO y MOSQUERA, 1998). La composición de ácidos grasos altamente insaturados del aceite de las semillas de zapallo hace que sea adecuado para mejorar los beneficios nutricionales de los alimentos (FU et al., 2006). Su importancia está dada además por su rusticidad y volumen de producción (4 - 5 frutos por planta), alimento saludable, mercado potencial de exportación, especialmente a los países europeos (HERNÁNDEZ, 2001).

\section{Componentes nutricionales del zapallo}

Las personas difieren en preferencia en cuanto a los componentes de sabor y grado de humedad del zapallo. No obstante, los conocedores de zapallo usualmente los prefieren relativamente secos en la pulpa, la textura ligeramente húmeda después de un proceso de cocción y un nivel alto de dulzura. Los altos niveles de azúcar no solo contribuyen a un sabor dulce deseable, también enmascara los componentes de sabor indeseables asociados con ciertas variedades, sabores que son adquiridos durante la cocción (LOY, 2007). Este mismo autor señala que, se puede estimar los niveles de azúcar fácilmente congelando una pequeña muestra el tejido y luego descongelar la muestra y presionar hasta obtener una gota de jugo claro y se mide los sólidos solubles del jugo en un refractómetro portátil. El contenido relativo de azúcar se da en unidades de porcentaje de sólidos solubles (Grados Brix), los niveles de sólidos solubles de $10 \%$ son pasables, pero generalmente los niveles de $11 \%$ o mayor son considerados zapallos de excelente calidad, la textura de la pulpa es atribuible al almidón, el contenido de almidón al momento de cosecha esta entre 45 a $55 \%$, mientras que el contenido de azúcar oscila entre el 10 a $15 \%$ con respecto a la materia seca del zapallo, por tanto, un zapallo con alto contenido de alta materia seca también tiene alto contenido de almidón (ORTIZ et al., 2013). Otros constituyentes menores de la materia seca en la pulpa son las proteínas, grasa, constituyentes de la pared celular (fibra cruda), y minerales (cenizas).

Además de los carbohidratos, la contribución nutricional principal del zapallo es el alto contenido de carotenoides, especialmente dentro de las especies $C$. máxima y $C$. moschata (ARIMA y RODRÍGUEZ, 1990). El Betacaroteno es un carotenoide abundante en varias variedades de zapallo, es un importante precursor de vitamina $A$, este caroteno cumple diversas funciones en el organismo como aumento del sistema inmune, disminución del riesgo de enfermedades degenerativas tales como envejecimiento celular, cáncer, enfermedad cardiovascular, arteriosclerosis, degeneración macular relacionada a la edad y formación de cataratas. Esto se debe a la propiedad antioxidante del $\beta$-caroteno, por la cual desactiva los radicales libres y atrapa los oxígenos singletes que provocan los efectos adversos mencionados previamente (RODRÍGUEZ-AMAYA, 2001).

\section{Calidad nutricional del fruto de zapallo}

El zapallo es una hortaliza que presenta frutos carnosos tipo baya (bacciforme), con un alto número de semillas dentro del fruto que varía de 300 a 700 semillas (ORTIZ et al., 2015), caracterizadas por su composición química rica en proteína, almidón y con contenidos de aceite que van desde el 30 al 50\% según la especie (VALDÉS, 2013). Si se incluye el fruto de zapallo en las raciones de los alimentos balanceados para animales ABA, se ganara en calidad nutricional, pues no solo aporta energía, sino también proteína (cuando menos 15\%) y carotenos totales (ORTIZ et al., 2008), que contribuirán a la pigmentación de los huevos y la piel de los pollos y se eliminaría el costo de carofiles y pigmentantes sintéticos de alto valor por ser importados. UBAQUE et al., (2015), reporta para la pigmentación de pollos de engorde, un valor de 6,39 en la escala de Roche, atribuidos a los carotenoides presentes en la harina de zapallo.

El fruto de zapallo C. moschata Duch., presenta un contenido de proteína cruda (PC) entre 4,4 y 14,5\%; pro vitamina A en forma de carotenos totales (CT) hasta $535(\mu \mathrm{g} / \mathrm{g})$, según MAYNARD et al., (2004) y entre 490,1 y 1.365,8 $(\mu \mathrm{g} / \mathrm{g})$ de CT según ORTIZ et al., (2008), digestibilidad de la materia seca (MS) superior al $80 \%$ (MAYNARD et al., 2004); características atractivas en términos nutricionales para consumo humano como fruto fresco y como fruto procesado en el diseño de raciones para animales. 
No obstante sus excelentes características nutricionales, se ven afectadas negativamente por el contenido de humedad del fruto que está alrededor del 90\% (ORTIZ et al., 2008), convirtiéndolo en un fruto perecedero, de corta vida, con los nutrientes diluidos, donde la longevidad del fruto y su capacidad para ser almacenado durante periodos prolongados depende del porcentaje de materia seca y su relación con almidones y azúcares en el mesocarpo (LACUZZO y DALLA COSTA, 2009).

Desde ese punto de vista, una humedad del $90 \%$ en el fruto fresco, no es rentable, ya que, su transformación en harina para ser involucrada en alimentos balanceados para animales aumentaría los costos de procesamiento del zapallo. Por tanto, la identificación de genotipos en las especies cultivadas, con niveles altos de materia seca (MS), sería la estrategia genética desde la perspectiva agroindustrial (ORTIZ et al., 2013), pues la mayor parte de las variedades e híbridos de zapallo existentes tanto nacionales como importados, son destinados para el consumo en fresco más no para procesos agroindustriales que incluyan transformación de la materia prima (VALDÉS, 2010).

Su inclusión en un programa de alimentos balanceados para animales, depende de la aptitud al proceso de deshidratación, operación unitaria costosa y con el consecuente daño que se puede ocasionar a la materia prima (ORTIZ et al., 2008).

Las semillas del género Cucurbita son consideradas oleaginosas con propiedades medicinales, alimenticias e industriales (ACHU et al., 2005). Las semillas se consumen enteras, asadas, tostadas o molidas y constituyen el principal ingrediente de las salsas. Las semillas constituyen el producto más importante, debido a su alto contenido de aceite (39\%) y proteína (44\%) (HERNÁNDEZ y LEÓN, 1994). Una variedad no mejorada de zapallo $C$. moschata, produce en promedio $400 \mathrm{~kg}$ de semilla/ha con un rendimiento de 200 litros de extracto etéreo por hectárea; que sobresale por su calidad para uso comestible, medicinal y agroindustrial (ORTIZ et al., 2013). La semilla de la especie Cucurbita pepo posee alto contenido de aceite, rico en ácidos grasos poliinsaturados, destacándose el linoleico (43$56 \%$ ) y el oleico (24-38\%), tocoferoles beta y gamma (vitamina E) y carotenoides: luteolina y beta-caroteno (LÓPEZ, et al., 2009).

En el mundo, el papel medicinal más difundido y popularizado de la semilla de zapallo se asocia con la concentración de extracto etéreo (aceite), y esto tiene una razón de ser supremamente importante; el extracto etéreo es sinónimo de energía y la energía es, básicamente, la capacidad para realizar un trabajo. En un sentido amplio, esto significa la capacidad de transformar (CASTRO et al., 2007). Bajo esta premisa, en Europa se consume el aceite de semillas de zapallo para aliviar o prevenir enfermedades relacionadas con la próstata, como aceite de cocina para ensaladas, debido a su alto contenido de ácidos grasos poliinsaturados de cadena larga (18:1 n-9) y como constituyente de otros alimentos comunes como el pan, mostaza y dulce (KOST'ÁLOVÁ et al., 2009). Se ha evaluado el contenido de extracto etéreo y proteína en la semilla, destacándose valores altos de proteína verdadera $(275$ a $318.3 \mathrm{~g} / \mathrm{kg})$ y extracto etéreo $(335,8$ a $346,3 \mathrm{~g} / \mathrm{kg}$ ), convirtiéndose en un alimento proteico y energético, además, el contenido de aminoácidos en la semilla es alto, principalmente en metionina, treonina, lisina y arginina (MARTÍNEZ, 2009).

En Grecia, el aceite proveniente de Cucurbita pepo se destaca como fuente alternativa para la producción de biodiesel (SCHINAS et al., 2008). En Colombia, el aceite proveniente de la semilla de Cucurbita moschata Duch. sobresale por el contenido de ácidos grasos insaturados $(55,28 \%)$ y una cantidad apreciable de ácido linoleíco $(55,11 \%)$. La torta proveniente de la semilla, contiene $(51.11 \%)$ de proteína y $(4.604,66 \mathrm{kcal} . /$ kg.) de energía (ORTIZ et al., 2008). La importancia del zapallo en la seguridad alimentaria a nivel nacional y la creciente demanda de nuevas materias primas para la agroindustria, viene fomentando de manera progresiva la investigación sobre esta hortaliza (VALDÉS, 2010).

El aceite de la semilla de Cucurbita maxima tiene propiedades antioxidantes (STEVENSON et al., 2007) y es reconocida por sus múltiples beneficios para la salud tales como, la prevención del crecimiento de la próstata, retardación en la progresión de la hipertensión, mitigación de la hypercolesterolemia y artritis, baja los niveles gástricos y previene el cáncer (STEVENSON et al., 2007).

En Australia, Eslovenia, Hungría y Serbia, la semilla proveniente de Cucurbita pepo se utiliza en la producción de aceite, el cual es utilizado en las comidas y el residuo seco del extracto de aceite, derivado del proceso de extracción, es usado en alimentación animal y como fertilizante (PERICIN et al., 2009). Los componentes fenólicos de las semillas oleaginosas, así como en la pulpa y cáscara (epicarpio) representan un potencial para la salud y para la industria (SHAHIDI, et al., 2006; WANG et al., 2007).

El aceite proveniente de semillas Cucurbita pepo, se produce a partir de dos subespecies: var. styriaca Greb y var. oleifera Pietsch (IDURAINE et al., 1996). El valor nutricional de las semillas se basa en el alto contenido de proteína $(61,4 \% \pm 2,6 \%)$ y energía debido al alto porcentaje de aceite. El contenido de aceite de la semilla es de $40 \%$ - $60 \%$; y de éste entre $98 \%$ - $99 \%$ del aceite son ácidos grasos oleico (por encima de 46,9\%), 
linolénico (por encima de 60,8\%), palmítico (por encima de $14,5 \%$ ), y esteárico (por encima de $7,4 \%$ ), con una proporción de ácidos monoinsaturados y poliinsaturados de 0,60 a 0,75 (NAKIĆ et al., 2006).

La materia seca del fruto de zapallo, presenta altas concentraciones de carotenoides (AZEVEDO-MELEIRO y RODRÍGUEZ-AMAYA, 2007), $\alpha$-caroteno, $\beta$-caroteno y luteína (NASCIMENTO, 2006). Estos últimos son importantes para humanos y animales; en tanto, en la ingesta son benéficos para mejorar la respuesta inmune, reducir el riesgo de enfermedades degenerativas como cáncer, enfermedades cardiovasculares y degeneración muscular (RODRIGUEZ-AMAYA y KIMURA, 2004).

Como en el acondicionado del fruto los carotenoides son susceptibles de degradación (RODRÍGUEZ-AMAYA y KIMURA, 2004), la pulpa se debe proteger de los efectos deletéreos de la luz, temperaturas altas y oxígeno del aire (RODRÍGUEZ-AMAYA, 1999).

La asociación directa entre color de la pulpa (C) y carotenos totales (CT) es positiva y altamente significativa; no obstante, no se puede concluir con razonable seguridad, que colores más intensos de la pulpa sean indicativo de mayor contenido de carotenos, puesto que los resultados obtenidos por ORTIZ (2013) al evaluar un gran número de poblaciones indican que no existe una correlación entre estos dos caracteres. De todos modos, independiente del color de la pulpa, el interés nutricional se centra en el contenido de carotenos totales, ya que un color intenso indica la presencia de carotenoides mas no de carotenos como tal, la gama de colores va desde el amarillo ( $\beta$-caroteno) pasando por el naranja y rojo (licopeno), es por ello, que un fruto intenso en color de pulpa no garantiza un incremento en la macromolécula de importancia, el $\beta$ caroteno (MARTÍNEZ, 2003).
Según ORTIZ et al., (2015), las correlaciones negativas entre materia seca del fruto vs carotenos totales y carotenos totales vs almidón, indican que el contenido de carotenos totales es inversamente proporcional al contenido de materia seca MSF y de almidón en el fruto. Esta asociación negativa se convierte en una barrera para el mejoramiento genético por calidad. Esta limitante podría superarse desarrollando nuevas estrategias como la identificación de genotipos con ambos caracteres en condición favorable o la selección recurrente recíproca entre poblaciones contrastantes para ambos caracteres o mediante retrocruzamiento de las poblaciones seleccionadas con un donante de alto contenido de carotenos.

Otro aspecto de gran importancia en el mejoramiento por calidad del fruto es la estrecha asociación entre el contenido de MSF y el contenido de Al. La selección por alto contenido de MS necesariamente conduce a un incremento significativo en el contenido de almidón $A L$, elemento de gran valor dado que es el $A L$ la macromolécula del fruto sobre la cual debe recaer el proceso de selección por MSF aprovechando la correlación genética altamente significativa entre los dos descriptores (ORTIZ et al., 2015). La importancia es notoria, en especial porque, para el control de calidad industrial, medir almidón es más costoso que medir materia seca en el fruto, tanto en términos monetarios como de protocolo e itinerario de técnicas y, además, porque el almacenamiento de frutos de zapallo durante periodos prologados, es directamente proporcional con los contenidos de materia seca, almidón y azúcares en el mesocarpio (LACUZZO y DELLA COSTA, 2009).

\section{REFERENCIAS}

ACHU, M.; FOKOU, E.; TCHIÉGAN, C.; FOTSO, M.; TCHOUANGUEP, F. 2005. Nutritive value of some Cucurbitaceae oil seeds from different regions of Cameroon. African J. Biot. 4(11):1329 - 1334.

ANDRES, T.C. 1987. Relationship of Cucurbita scabridifolia to C. foetidissima and C. pedatifolia, a case of natural interspecific hybridization. Cucurbit Genet. Coop. Rep. 10: 74-75.

ARIMA, H.K.; RODRÍGUEZ-AMAYA, D.B. 1990. Carotenoid composition and vitamin A value of squash and pumpkin from northeastern Brazil. Arch Latinoam Nutr 40:284-292.

AZEVEDO-MELEIRO, C.H.; RODRÍGUEZ-AMAYA, D.B. 2007. Qualitative and quantitative differences in carotenoid composition among Cucurbita moschata. Cucurbita maxima and Cucurbita pepo. Journal of Agricultural and Food Chemistry 55 (10) 4027-4033.

BAILEY, L. H. 1943. Las especies de Cucurbita. Gentes Herbarum (Ithaca, NY) 6: 267 a 322. 
BEMIS, W.P.; WHITAKER, T.W. 1969. The xerophytic cucurbita of northwestern Mexico and southwestern United States. Madroño 20 (2):33-41.

BEMIS, J.; CURTIS, L.; WEBER, C.; BERRY, J. 1978. The Feral Buffalo Gourd, Cucurbita foetidissima. Economic Botany 1:87-95.

CARTAY, R. 1991. Historia de la alimentación del Nuevo Mundo. San Cristóbal, Venezuela, Ed. futuro. 2 vol.

CASTRO, P.; COELLO, J.; CASTILLO, L. 2007. Opciones para la producción y uso del biodiesel en el Perú. Soluciones Prácticas-ITDG. Lima, Perú. Pp. 176.

CERÓN, G.L.; LEGARÍA, S.J.P.; VILLANUEVA, V.C.; CASTELLANOS, J.S. 2010. Diversidad genética en cuatro especies mexicanas de calabaza (Cucurbita spp.). Rev. Fitotec. Mex. 33 (3):189 - 196.

CUTLER, H.C.; WHITAKER, T.W. 1969. A new species of Cucurbita from Ecuador. Ann Missouri Bot. Gard. 55 392-396.

DECKER-WALTERS, D.S.; STAUB, J.E.; CHUNG, S.M.; NAKATA, E.; QUEMADA, H.D. 2002. Diversity in free-living populations of Cucurbita pepo (Cucurbitaceae) as assessed by random amplified polymorphic DNA. Syst. Bot. 27 (1):19-28.

ESTRELLA, E. 1990. El pan de América. Etnohistoria de los alimentos aborígenes en el Ecuador. Quito, Ecuador, Ed. Abya-Yala, 3a edición.

FAOSTAT. 2013. Food and agriculture Organization of the United Nations. Tomado de: http://faostat3.fao.org/home/ index es.html?locale=es\#DOWNLOAD

FU, C.; SHI, H.; LI, Q. 2006. A review on pharmacological activities and utilization technologies of pumpkin. Plant Foods Hum. Nutr. 200661 (2):73-80.

HERNÁNDEZ, B.J.E.; LEÓN, J. 1994. (eds.) Neglected crops: 1492 from a different perspective. Roma: FAO. ISBN 92-5-103217-3.

HERNÁNDEZ, C.J.M. 2001. Programa nacional de recursos genéticos. Disponible en internet: URL:http://fwl.inifap. conacyt.mx/progs a/agricola/prog rec fitoge.html

HIDALGO, H.R.; VALLEJO, C.F.A. 2014. Bases para el estudio de recursos genéticos de especies cultivadas. Universidad Nacional de Colombia, Palmira. ISBN: 978-958-775-100-0.

IDOURAINE, A.; KOHLHEPP, E. A.; WEBER, C.W.; WARID, W.A.; MARTINEZ-TELLEZ, J.J. 1996. Nutrient constituents from eight lines of naked seed squash (Cucurbita pepo L.). J. Agr. Food Chem. 44:721-724.

JEFFREY, C. 1990. Appendix. An outline classification of the Cucurbitaceae. Págs. 3-9. En: Bates, D.M.; Robinson, W.R.; Jeffrey, C. (eds.). Biology and utilization of the Cucurbitaceae. Cornell University Press. Ithaca, Nueva York.

KRAUTGARTNER, R. 2006. Grain report of USDA Foreign Agricultural Service.

http://www.fas.usda.gov/gainfiles/200806/146294845.pdf.03/06/07. Fecha de acceso: 3/16/2015.

KOST'ÁLOVÁ, Z.; HROMÁDKOVÁ, Z.; EBRINGEROVÁ, A. 2009. Chemical evaluation of seeded fruit biomass of oil pumpkin (var. Styaca): chemical Papers. 63:406.

LACUZZO, F.; DALLA, C.L. 2009. Yield performance, quality characteristics and fruit storability of winter squash cultivars in sub-humid areas. Sci. Hortic. 2009:10-16.

LEBEDA, A.; WIDRLECHNER, M.P.; STAUB, J.; EZURA, H.; ZALAPA, J.; KFISTOVÁ, E. 2007. Cucurbits (Cucurbitaceae; Cucumis spp., Cucurbita spp., Citrullus spp.). Págs. 271-376. En: Singh, R.J. (ed). Genetic Resources, Chromosome Engineering, and Crop Improvement. Vol. 3. Vegetable Crops. CRC Press. Boca Raton, FL, USA. 
LIRA, S.R. 1995. Estudios taxonómicos y ecogeografía de las Cucurbitaceas Latinoamericanas de importancia. Economía. Instituto de Biología. UNAM, México e IPGRI. .

LIRA-SAADE R. 2001. Cucurbitaceae._Flora del Bajío y de Regiones Adyacentes. Fascículo 92._Trabajo realizado con el apoyo económico de la Comisión Nacional para el Conocimiento y Uso de la Biodiversidad, a través del proyecto Q010 .Estado actual y fitogeografía de las especies de la familia Cucurbitaceae endémicas de México.

LÓPEZ, H.O.D.; MÁRQUEZ, C.T.; SALOMÓN, I.S.; GONZÁLEZ, S.M.L. 2009. Extracción de lípidos de las semillas de Cucurbita pepo L. (calabaza). Centro de Investigación y Desarrollo de Medicamentos. CIDEM. Ciudad de la Habana. Cuba.

LOY, B. 2007. Vegetable notes, for vegetable farmers in Massachusetts. Department of Plant Biology University of New Hampshire. August 30. 18 (17):1.32.

MARTÍNEZ, M A. 2003. Carotenoides. Universidad de Antioquia. Medellin, Colombia.

MARTÍNEZ, A.Y. 2009. Caracterización química de la harina de semilla de calabaza (Cucurbita) y su empleo en la alimentación de gallinas ponedoras y pollos de ceba. Tesis Doctoral en ciencias Veterinarias. Universidad de Granma.

MAYNARD, D.N.; ELMOSTROM, G.W.; TALCOTT, S.T.; CARLE, R.B.; CARLE, R.B. 2004. El Dorado and La Estrella: Compact Plant Tropical Pumpkin Hybrids. Tomado de: http://gcrec.ifas.ufl.edu/tpmanuscript.htm 05/06/2015 10:30:15 a.m.

MERRICK, L.C. 1990. Systematics and evolution of a domesticated squash, Cucurbita argyrosperma, and its wild and weedy realtives. Págs. 77-95. En: Bates, D.M.; Robinson, R.W.; Jeffrey, C (eds.). Biology and utilization of the Cucurbitaceae. Ithaca, N.Y.

NAKIĆ, S.N.; RADE, D.; KEVIN, D.; ŠTRUCELJ, D.; MOKROVČAK, Z.; BARTOLIĆ, M. 2006. Chemical characteristics of oils from naked and husk seeds of Cucurbita pepo L. Eur. J. Lipid Sci. Technol. 108:936-943.

NASCIMENTO, P. 2006. Avalição da retenção de carotenóides de abóbora, mandioca e batata doce. Dissertação Mestrado (Eng Ciência Alimento). São José do Rio Preto: Universidade Estadual Paulista. 67f Tomada de: http//www.biblioteca.unesp.br/bibliotecadigital/document/get.php/4133/nascimento_p_me_sjrp.pdf. Acceso: 21/08/2015.

NEE, M. 1990. The Domestication of Cucurbita (Cucurbitaceae). Economic Botany (New York: New. York Botanical Gardens Press 44 (3):56-68.

ORTIZ, G.S.; SÁNCHEZ, L.J.; VALDÉS, R.M.P.; BAENA, G.D.; VALLEJO, C.F.A. 2008. Retención de caroteno total en fruto de zapallo Cucurbita moschata Duch. acondicionado por osmodeshidratación y secado. Acta Agronómica 57 (4):269-274.

ORTIZ, G.S.; VALLEJO, C.F.A.; BAENA, G.D.; ESTRADA, S.E.I.; VALDÉS, R.M.P. 2013. Zapallo para consumo en fresco y fines agroindustriales: Investigación y desarrollo. Universidad Nacional de Colombia, Sede Palmira. Santiago de Cali, Feriva. Colombia

ORTIZ, G.S.; VALDÉS, R.M.P.; VALLEJO, C.F.A.; BAENA, G.D. 2015. Genetic Correlations and Path Analysis in Butternut Squash Cucurbita moschata Duch. Rev. Fac. Nal. Agr. Medellín 68 (1): 7399-7409.

PÉREZ, A.E. 1978. Plantas útiles de Colombia.4 $4^{\text {nd }}$ ed. Bogotá. Litografía. Aico.

PERICIN, D.; KRIMER, V.; TRIVIC, S.; RADULOVIC, L. 2009. The distribution of phenolic acids in pumpkin's hullless seed, skin, oil cake meal, dehulled kernel and hull. Journal food chemistry 113:450-456.

PIPERNO, D.R.; STOTHERT, K.E. 2003. Phytolith evidence for early Holocene Cucurbita domestication in southwest Ecuador. Science:1054-1055. 
PROVVIDENTI, R. 1990. Viral diseases and genetic sources of resistance in Cucurbita species. Págs. 427-435. En: Bates, D.M.; Robinson, R.W.; Jeffrey, C. (eds.). Biology and Utilization of the Cucurbitaceae. Cornell University Press, Ithaca, New York.

PUCHALSKI, J.T.; ROBINSON, R.W. 1990. Electrophoretic analysis of isozymes in Cucurbita and Cucurmis and its application for phylogenetic studies. Págs. 60-76. En: Bates, D.M.; Robinson, R.W.; Jeffrey, C. (eds.). Biology and utilization of the Cucurbitaceae. Ithaca, N.Y.

ROBINSON, R.W.; MUNGER, H.M.; WHITAKER, T.W.; BOHN, G.W. 1976. Genes of the Cucurbitaceae. Hort Science (USA): 11(6): 554-568.

RODRIGUEZ-AMAYA. D. 1999. Changes in carotenoids during processing and storage of foods. Arch Latinoam Nutr 49(1-S): 38-47.

RODRÍGUEZ-AMAYA, D. B. 2001. A guide to carotenoid analysis in food. ILSI Press:5-10.

RODRÍGUEZ-AMAYA, D.B.; KIMURA, M. 2004. Handbook for Carotenoid Analysis. Washington, DC: IFPRI-CIAT. 63 p. (HarvestPlus Technical Monograph 2).

SANJUR, O.I.; PIPERNO, D.R.; ANDRÉS, T.C.; WESSEL-BEAVER, L. 2002. Phylogenetic relationships among domesticated and wild species of Cucurbita (Cucurbitaceae) inferred from a mitochondrial gene: Implications for crop plant evolution and areas of origin. Proceedings of the National Academy of Sciences 99 (1):535-540.

SCHINAS, P.; KARAVALAKIS, G.; DAVARIS, C.; ANASTOPOULOS, G.; KARONIS, D.; ZANNIKOS, F.; STOURNAS, S.; LOIS, E. 2008. Pumpkin (Cucurbita pepo L.) seed oil as an alternative feed stockf or the production of biodiesel in Greece. Elsevier. 10.1016/j.biombioe.2008.04.008.

SHAHIDI, F.; LIYANA-PATHIRANA, C.M.; WALL, D.S. 2006. Antioxidant activity of white and black sesame seeds and their hull fractions. Food Chemistry 99:478-483.

SINGH, A.K. 1990. Cytogenetics and evolution in the Cucurbitaceae. Págs. 10-16. En: Bates, D.M.; Robinson, R.W.; Jeffrey, C. (eds.). Biology and utilization of the Cucurbitaceae. Ithaca, N.Y.

SMART, J.; SIMMONDS, N.W. 1995. Evolution of crop plants. Segunda edición. Longmann Scientific and technical.

SMITH, B.D. 1997. The initial domestication of Cucurbita pepo in the Americas 10,000 years ago. Science 276:932934.

STEVENSON, D.G.; ELLER, F.J.; WANG, L.; JANE, J.L.; WANG, T.; INGLETT, G. 2007. Oil andtocopherol content and composition of pumpkin seed oil in 12 cultivars. Journal of Agricultural and Food Chemistry 55:4005-4013.

UBAQUE, C.C.; OROZCO, L.V.; ORTIZ, G.S.; VALDÉS, R.M.P.; VALLEJO C.F.A. 2015. Sustitución del maíz por harina integral de zapallo en la nutrición de pollos de engorde. Rev. U.D.C.A act. \& div. cient. 18 (1):137-146.

VALDÉS, R.M.P.; ORTIZ, G.S.; BAENA, G.D.; VALLEJO, C.F.A. 2010. Evaluación de poblaciones de zapallo Cucurbita moschata Duch. por caracteres de importancia agroindustrial. Acta Agronomica 59 (1):91-96.

VALDÉS, R.M.P., ORTIZ, G.S.; VALLEJO, C.F.A.; BAENA, G.D. 2014. Variabilidad en frutos y semillas de Cucurbita moschata Duch. y Cucurbita argyrosperma subsp. sororia L.H. Bailey Merrick \& D.M. Bates. Acta Agronómica 63 (2):282-293.

VALEGA, R. R.; ANDRES, T.; NEE, M. 2004. The Goldman Cucurbit Collecting Expedition in Peru. Disponible en: http://www.cucurbit.org.

VALLEJO, C.F.A.; MOSQUERA, S.E. 1998. Transferencia del gen Bu a poblaciones de zapallo, Cucurbita sp. con crecimiento postrado. Acta Agronómica 48:7-18. 
VALLEJO, C.F.A.; ESTRADA, S.E.I. 2004. Producción de hortalizas de clima cálido. Universidad Nacional de Colombia, Sede Palmira. Imágenes Gráficas. ISBN: 958-8095-28. p. 191.

WANG, J.; YAUN, X.; JIN, Z.; TIAN, Y.; SONG, H. 2007. Free radical and reactive oxygenspecies scavenging activities of peanut skins extracts. Food Chemistry 104:242-250.

WATSON, S. 1879. Revision of the North American Liliaceae: Descriptions of Some New Species of North American Plants. Proceedings of the American Academy of Arts and sciences XIV: 213-312. doi: 10.2307/25138538. JSTOR 25138538.

WHITAKER, T.W. 1947. American origin of the cultivated cucurbits. Ann. Missouri Bot. Gard. 34:102-111.

WHITAKER, T.V. 1962. Cucurbits. University Press, London.

WHITAKER, T.; CUTLER, H. 1971. Prehistoric cucurbits from the Valley of Oaxaca. Economic Botany 25: $123-127$.

WHITAKER, T.J.; DAVIS, G. 1962. Cucurbits: botany, cultivation and utilization. New York, Interscience.

WHITAKER, T.W.; BEMIS, W.P. 1975. Origen y evolución del cultivo Cucurbita. Bull Torrey Bot club 102:362-368.

WHITAKER, T.W. 1981. Archeological cucurbits. Econ Bot 35 (4):460-466.

WORLD'S HEALTHIEST FOODS (WHF). 2008. Pumpkin seeds. The George Mateljan Foundation. September 18, 2008. Acceso: 05-04-10. Disponible en: http://www.whfoods.com/genpage.php?tname=food\&spicedbid=82\#healt $\underline{\text { hbenefits }}$ 